\title{
Biochemical and physicochemical characteristics of the major muscle proteins from fish and shellfish
}

\author{
Yoshihiro Ochiai $^{1}\left[\right.$ Hideo Ozawa ${ }^{2}$
}

Received: 3 May 2020 / Accepted: 23 June 2020 / Published online: 21 July 2020

(c) The Author(s) 2020

\begin{abstract}
Fish and marine invertebrates constitute an important part of the human diet worldwide, and their muscles are the major edible parts. The muscles are a rich source of proteins, which in other terms determines the nutritional value and the quality of seafood products. Though the fish skeletal muscle proteins share many similarities with their mammalian counterparts, there exist great differences in their biological activity and structural stability. While the muscles of shellfish or aquatic invertebrates share many properties and general structural features with their vertebrate counterparts, they have unique characteristics. Therefore, understanding the biochemical and physicochemical properties of their major protein components is needed from the viewpoint of effective utilization of aquatic bioresources. Thus, in this review, we aimed to assemble the basis of such differences and also to understand the benefits of these proteins as the targets for studies on the structure-stability relationship of proteins.
\end{abstract}

Keywords Fish $\cdot$ Shellfish $\cdot$ Muscle proteins $\cdot$ Stability $\cdot$ Structure $\cdot$ Characterization $\cdot$ Physiological functions

\section{Introduction}

Many species of fish and shellfish are used for food, constituting an important part of the human diet. Muscles, the major edible part of fish and shellfish, are the tissues that have evolved uniquely and can function in many ways to control their locomotion and posture. The muscles from fish and shellfish share many properties and general structural features with those from terrestrial animals. Therefore, information on muscle structure and function could be very helpful for understanding the characteristics of different seafood products.

Based on their structure and function, muscles are classified into striated and smooth muscles, and the former in

Published with support by the Japan Society for the Promotion of Science (JSPS) KAKENHI Grant no. JP19HP2002.

Yoshihiro Ochiai

yochiai@tohoku.ac.jp

1 Graduate School of Agricultural Science, Tohoku University, Aramaki, Aoba, Sendai, Miyagi 980-8572, Japan

2 Faculty of Applied Bioscience, Kanagawa Institute of Technology, 1030 Shimo-Ogino, Atsugi, Kanagawa 243-0292, Japan vertebrates is further categorized into skeletal and cardiac muscles. The skeletal muscle is further categorized into fast and slow skeletal muscles. This classification is also true for invertebrates, because slow-type muscles have also been found in invertebrates, such as crab (Ochiai et al. 1988) and octopus (Kariya et al. 1986).

In 2013, total captured and farmed aquatic animal food products accounted for $16.3 \%$ of the animal protein intake by the global population and provided more than 3.1 billion people with at least $20 \%$ of their average per capita intake of total animal protein (FAO 2013). Thus, fish and shellfish can be used as an efficient meat replacement in meat-eating countries, thanks to their lower environmental impact than livestock animals that are fit for human consumption (de Boer et al. 2020). The muscle proteins generally comprise water-soluble sarcoplasmic proteins, salt-soluble myofibrillar proteins, and insoluble stroma proteins, which occupy about $20-50 \%, 50-70 \%$, and $3 \%$ (in the case of fish) of the total muscle protein, respectively (Hashimoto et al. 1979). The composition of these proteins also varies. For example, the sarcoplasmic protein contains the glycolytic enzymes, creatine kinase, myoglobin, and parvalbumin; the myofibrillar protein contains myosin, actin, tropomyosin, troponin, and paramyosin (in many invertebrate species), whereas the 
stroma protein mainly consists of extracellular matrix proteins such as collagen.

The characteristic properties of the major muscle proteins are the important quality determiners of raw muscle as well as fish and seafood products. For this reason, information on the protein components is important for developing strategies for optimum preservation and processing conditions, effective utilization, and furthering the hygiene of aquatic animals. Therefore, in this review, we focus on the major components of fish and shellfish muscle proteins, specifically the biochemical and physicochemical properties of the striated muscle proteins.

\section{Characteristics of the major proteins in muscles}

The major part of the fish musculature consists of fast skeletal (ordinary) muscle and slow skeletal (dark) muscle (Okagaki et al. 2005). The characteristics (molecular weight, isoelectric point, sequence profiles) of the major fish and shellfish muscle proteins are listed in Table 1. The numbers of amino acid residues of the listed proteins varies from 109 to 31,468 , corresponding to $11,545 \mathrm{Da}$ to $3,496,849 \mathrm{Da}$, respectively. Most of the proteins have acidic isoelectric points, except the troponin I subunit and myoglobin. The differences in amino acid sequence can greatly affect the higher-order (secondary and tertiary) structures of the orthologous proteins as well as their physiological properties and stability.

\section{Myosin}

Myosin constitutes approximately $60 \%$ of the total mass of skeletal muscle protein. This protein is salt-soluble and is a hexamer, consisting of two heavy chain subunits of approximately $200 \mathrm{kDa}$ and four light chain subunits of approximately $20 \mathrm{kDa}$ (Table 1). The total molecular weight is thus close to 500,000. Based on the molecular shape and biological functions, myosin forms a superfamily, consisting of at least 15 classes (Hartman and Spudich 2012). Muscle myosins are categorized as type II, characterized by the two globular heads and a long single tail, which forms a thick filament under physiological conditions (Franzini-Armstrong and Sweeney 2012).

\section{Molecular structure}

The head portion (approx. $20 \mathrm{~nm} \times 7 \mathrm{~nm}$ ) is connected to an elongated tail (rod) (approx. $140 \mathrm{~nm} \times 2 \mathrm{~nm}$ ). Genomic analyses have revealed that the muscle myosins, among a variety of myosins, have evolved especially for muscle contraction. However, the structure and functions of the head portions, which generate contractile power over actin filament through

Table 1 Profiles of the major muscle proteins

\begin{tabular}{|c|c|c|c|c|c|}
\hline Proteins & Source & $\begin{array}{l}\text { Amino acid } \\
\text { residues }\end{array}$ & Molecular weight & Isoelectric point & Accession number ${ }^{\mathrm{a}}$ \\
\hline Myosin & Carp Cyprinus carpio & & & & \\
\hline Heavy chain & & 1935 & 221,600 & 5.56 & BAA22069 \\
\hline Light chain (LC3) & & 151 & 16,845 & 4.40 & BAA12733 \\
\hline Actin & $\begin{array}{l}\text { Walleye pollock } \\
\text { Gadus chalcogrammus }\end{array}$ & 377 & 41,959 & 5.23 & AB073379 \\
\hline Tropomyosin & $\begin{array}{l}\text { Tilapia } \\
\text { Oreochromis mossambicus }\end{array}$ & 284 & 32,698 & 4.69 & QBY26063 \\
\hline Troponin & Zebrafish Danio rerio & & & & \\
\hline T subunit & & 284 & 33,599 & 5.51 & NP_001103886 \\
\hline I subunit & & 176 & 19,733 & 9.25 & NP_991138 \\
\hline C subunit & & 160 & 18,211 & 3.96 & AF180890 \\
\hline Paramyosin & $\begin{array}{l}\text { Scallop } \\
\text { Mizuhopecten yessoensis }\end{array}$ & 934 & 107,548 & 5.62 & OWF54321 \\
\hline Titin (connectin) & D. rerio & 31,468 & $3,496,849$ & 6.10 & XP_021334745 \\
\hline$\alpha$-Actinin & D. rerio & 898 & 103,860 & 5.17 & NP_991107 \\
\hline Parvalbumin & Mackerel Scomber japonicus & 109 & 11,545 & 5.15 & EF016113 \\
\hline Myoglobin & $\begin{array}{l}\text { Blackfin tuna } \\
\text { Thunnus atlanticus }\end{array}$ & 147 & $15,628^{\mathrm{b}}$ & 8.99 & AB 104433 \\
\hline
\end{tabular}

${ }^{\mathrm{a}}$ GenBank

${ }^{\mathrm{b}}$ Without a heme 
ATP hydrolysis, are shared by all the myosins (Hartman and Spudich 2012).

When myosin is treated with proteolytic enzymes under a given condition, several major fragments which retain the biological functions of myosin are obtained. When treated with chymotrypsin in the presence of $\mathrm{Ca}^{2+}$, the myosin molecule is cleaved to heavy meromyosin (HMM) comprising the two heads with a short tail (subfragment 2 or S-2), and light meromyosin (LMM) corresponding to the major part of the rod. HMM is water-soluble and has binding sites for both actin and ATP, but cannot form a filament. By papain treatment, HMM can be fragmented to the head portion (subfragment 1 or S-1) and S-2. S-1 retains the important biological functions of myosin, namely, ATPase activity and actin binding. The tertiary structure of S-1 from the scallop adductor striated muscle has been determined (Fig. 1a). Light chain subunits are non-covalently bound to the 'neck region' (or a lever arm) of the heavy chain. By comparing the amino acid sequences of S-1s from different animal sources, many substitutions are found in the loop regions which protrude to the surface of the molecule and the light chain binding sites. In contrast, much fewer substitutions occur in the ATP and actin-binding sites (Wang et al. 2018). On the other hand, myosin heavy chains of the adductor striated and smooth muscles of scallop have different amino acid sequences, but the products of a single gene through alternative splicing (Nyitray et al. 1994).

Myosin is a kind of a linear nanomotor, running along the 'rail' of the actin filament (F-actin). Upon binding of ATP to the head, followed by the on-site hydrolysis into ADP and inorganic phosphate, chemical energy is provided for muscle contraction, which is based on the bending of the myosin head, with the lever arm pulling back the actin filament, just like pulling an oar (a lever arm hypothesis, a sliding theory of muscle contraction). Franzini-Armstrong and Sweeney (2012) have described the contraction mechanism of skeletal muscle in detail.

Under the physiological ionic strength, the rod forms a thick anisotropic filament through lateral polymerization of the adjacent molecules and is thus recognized as a dark band (anisotropic band, A band) in the microscopic structure of muscle fibers. The rod is filamentous and has a coiled-coil structure formed by winding of two $\alpha$-helices along the molecule (Fig. 1b, d). This motif is also found in the filamentous proteins, tropomyosin, and paramyosin which are to be described later. The coiled-coil structure is formed by the repetition of seven residues (heptad repeat, designated in the order of $a, b, c, d, e, f$, and $g$ from the $\mathrm{N}$-terminus), with hydrophobic residues preferentially located at the $a$ and $d$ positions providing hydrophobic interaction, and with charged residues located at the $e$ and $g$ positions providing salt bridges. These interactions stabilize the interface of the two subunits (Fig. 1d) (Perry
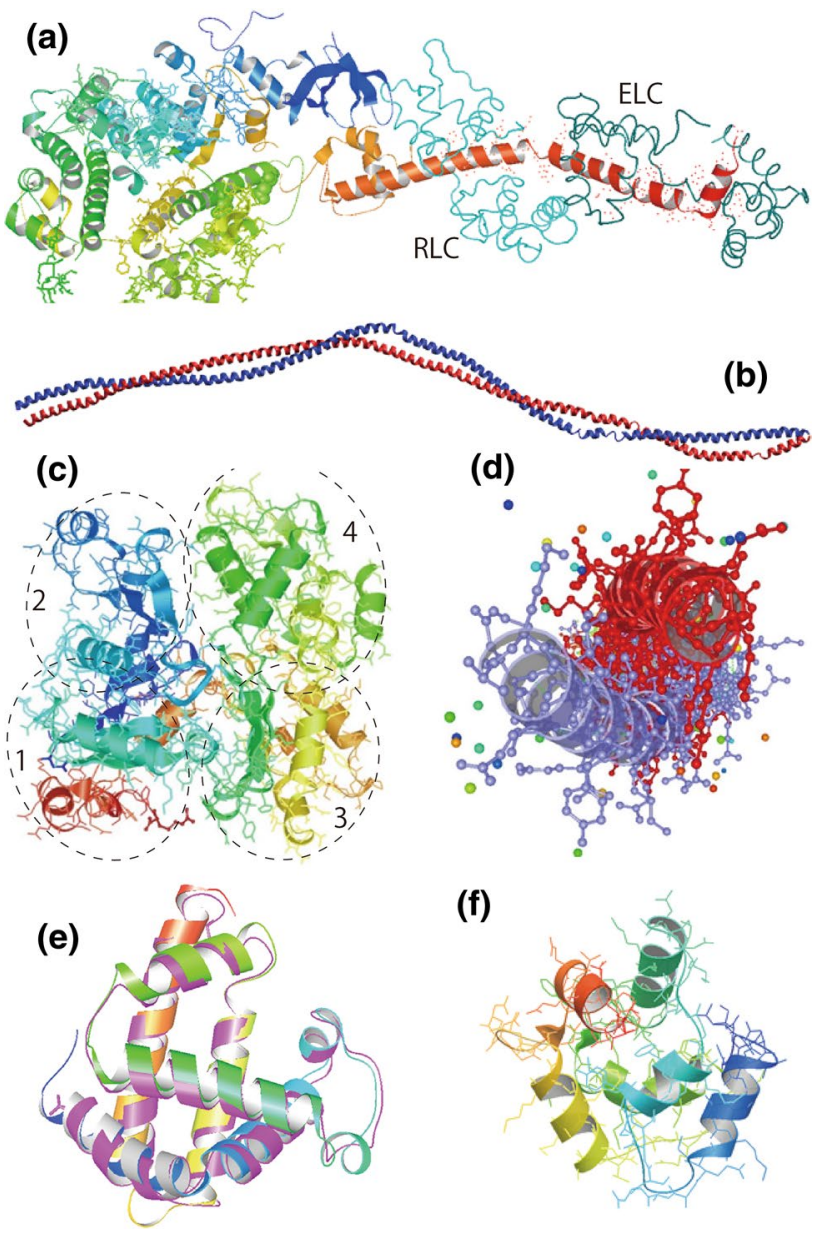

(f)

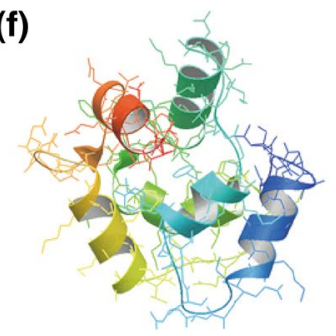

Fig. 1 The tertiary structures of the proteins referred to in this review. a Myosin subfragment 1 from scallop Argopecten irradians adductor muscle (PDB ID: 1L2O). RLC and ELC stand for the regulatory light chain and essential light chain, respectively. b Kuruma prawn Marsupenaeus japonicus tropomyosin (after $10 \mathrm{~ns}$ of molecular dynamics simulation using $1 \mathrm{C} 1 \mathrm{G}$ as a template) (Ozawa et al. 2018). c Japanese flying squid Todarodes pacificus actin (modeled structure based on rabbit actin ADP form, 1J6Z, Ochiai et al. 2013). The subdomains 1 through 4 are roughly encircled with broken lines. d Cross-section of rabbit tropomyosin (2D3E). A view from the N-terminus. The two subunits are distinguished in blue and red. e Superimposition of bluefin tuna myoglobin (modeled structure based on blackfin tuna $T$. atlanticus myoglobin 2NRL) in purple and sei whale Balaenoptera borealis myoglobin in the color spectrum based on the structure of sperm whale myoglobin (1A6G). The hemes are not included. f Whiting Merlangius merlangus parvalbumin (1A75). a, b are in a ribbon model except the light chains in a wire model, $\mathbf{c}, \mathbf{e}, \mathbf{f}$ are in a ribbon model with the amino acid residues in a stick model, and $\mathbf{d}$ is in a ribbon model of the backbone structure. In $\mathbf{a}, \mathbf{c}, \mathbf{e}, \mathbf{f}$, the direction from the N-terminus (blue) to the C-terminus (red) is shown with the color spectrum (color figure online)

2001). In the rod region, there are some 'skip residues', which disturb the heptad repeat and thus the coiled-coil structure. These residues, found in mammalian myosins as well as invertebrate counterparts, seem to favor the partial bending of the rod (Matulef et al. 1998). 
The coiled-coil structure decays by increase of the ambient temperature, and the extent of decay can be measured as the decrement of $\alpha$-helical content by circular dichroism (CD) measurement and as transition temperature by microcalorimetry (or differential scanning calorimetry, DSC) (Fukushima et al. 2003). Therefore, the LMM and S-2, which have nearly complete helical structures, are considered to be excellent model proteins for studying the structure-stability relationship of proteins. The amino acid sequences are very informative to understand the biochemical and physicochemical properties of these fragments. In contrast, the structure of the head portion (Fig. 1a) is too complicated to annotate the spectral and thermodynamic changes to the partial structural ones.

The thermal denaturation mechanism and limited proteolytic patterns provide valuable information for understanding the structural changes and denaturation mechanism (Hamai and Konno 1990; Satoh et al. 2006). The domain structures (substructures) and thermal denaturation profile of fish $\mathrm{S}-1 \mathrm{~s}$, as examined by tryptic treatment, are similar to those of rabbit counterparts (Franzini-Armstrong and Sweeney, 2012). Fish S-1s also consist of $27 \mathrm{~K}(25 \mathrm{~K}), 50 \mathrm{~K}$, and $20 \mathrm{~K}$ domains (of approx. $27 \mathrm{kDa}, 50 \mathrm{kDa}$, and $20 \mathrm{kDa}$, respectively) in this order from the $\mathrm{N}$-terminus, like those of higher vertebrates. However, light chains tend to dissociate from the $\mathrm{S}-1$ heavy chain faster as compared to the mammalian counterparts and the heavy chains also tend to increase turbidity under heat treatment (Hamai and Konno 1990).

\section{Light chain subunits}

Fast skeletal myosins, including those of fish, have three kinds of light chains, which are generally designated LC1, LC2, and LC3 in order of decreasing molecular weight. Based on the physiological functions, light chains are categorized into the essential and regulatory ones. Essential light chains (ELCs) are also called alkali light chains, because they are dissociated from the heavy chain by alkaline treatment. Muscle myosins have two ELCs and two regulatory light chains (RLCs). The two isoforms of the ELCs are designated as A1 and A2 with the decreasing molecular weight, corresponding to LC1 and LC3 in most species. Mammalian and avian ELCs are the products from a single gene through alternative splicing, while fish ELCs are encoded in different genes (Libera et al. 1991; Hirayama et al. 1997).

The physiological function of ELCs has not yet been established, but is believed to reinforce the neck region of myosin, where physical loading takes place during muscle contraction. A1 has an additional region called 'difference peptide' of about 40 residues at the $\mathrm{N}$-terminus compared with A2. Myosin S-1 isoforms (isozymes) associating A1 or A2, namely, S-1 (A1) and S-1 (A2), show different actinactivated $\mathrm{Mg}$-ATPase activity as well as different thermal stability (Wagner et al. 1979; Ochiai et al. 1989). The myosin head associating different ELCs could perform different reactions with actin, probably due to the binding of the different peptide to actin, but the physiological significance of such differences needs to be explored further (Guhathakurta et al. 2018). On the contrary, the RLC, corresponding to LC2 in most species, dissociates from the heavy chain by the treatment with a kind of sulfhydryl reagent, 5,5'-dithiobis(2nitrobenzoic acid) (DTNB), and thus is also called DTNB light chain. In molluscan myosins, the RLC, which is responsible for myosin-linked regulation of muscle contraction, dissociates in the presence of EDTA, a divalent ion chelator, and thus is called EDTA light chain. Incidentally, myosins from slow skeletal muscle and cardiac muscle generally contain two pairs of RLCs and ELCs with no isoforms (Watabe et al. 1983; Dinh et al. 1985).

The molecular weight distribution of fish ELCs is quite species-specific (Watabe et al. 1982; Ochiai et al. 1990). Especially, Scombridae species, such as tunas, have A1 of extraordinarily high molecular weight (approx. $30 \mathrm{kDa}$ ), whereas A2 has a higher molecular weight than the DTNB light chain. The additional region at the $\mathrm{N}$-terminus of tuna A1 is not clear, unlike those of higher vertebrates. The structure of pollack A1 resembles those of the mammalian counterparts, whereas that of DTNB light chain is very conservative against molecular evolution.

\section{Molecular adaptation and diversity}

ATPase activity, actin-binding ability, filament formation, and structural stability of myosin are variable depending on species and tissues, and may change through acclimation to habitat environment, especially temperature (Somero 2003). Myosins from carp fast skeletal (ordinary) and slow skeletal (dark) muscles show clear differences in these aspects (Okagaki et al. 2005). Specific ATPase activity of dark muscle myosin has been reported to be about twofold higher compared to those of mammalian slow muscles. The differences in these myosins correspond to the characteristics of the respective muscles (Watabe et al. 1983; Shuman and Coughlin 2018) and can be attributed mostly to those of heavy chains.

Cyprinidae species such as carp express myosin heavy chain isoforms according to seasonal changes. The thermostability of the myosin rod from grass carp Ctenopharyngodon idella is higher during the summer season than the winter season, with the difference being ascribed to the stability of S-2 (Yuan et al. 2011). This is considered to be a kind of trade-off between activity and stability to facilitate locomotion during the cold season (Watabe 2002). Such a tradeoff has also been found between the proteins from tropical and Antarctic fish species (Gauvry et al. 2000). Moreover, replacement and loss of amino acid residues have been found 
in the myosin heavy chains from deep-sea fish species in relation to adaptation to the environment or high hydraulic pressure (Morita 2008). Namely, the sequences of myosin heavy chains from the genus Coryphaenoides show that the deep-sea species have proline, a helix breaker, in loop-1, and a shorter loop-2, one of the actin-binding regions, in comparison with the less-deeper species. In addition, the residues located at the interface of the coiled-coil in the rod are relatively smaller in the deep-sea species, making the overall structure more compact.

Elasmobranchs (sharks and rays) and lungfish accumulate a high concentration of urea, a protein denaturant, in their tissues, including the muscle, for osmoregulation. Their myofibrillar proteins show resistance to urea to some extent (Kanoh et al. 2000). These fish and also many deep-sea species accumulate a comparable amount of trimethylamine oxide (TMAO), depending on the depth of their habitat, which counteracts the action of urea and also protects the proteins from denaturation caused by high hydraulic pressure (Yancey et al. 2001).

\section{Paramyosin}

Paramyosin is found in a large amount in the muscles of most invertebrates. For example, the top shell muscle and oyster adductor muscle contain around $40 \%$, while the scallop adductor (smooth muscle) and octopus arm contain around 30\% (Ochiai et al. 1985; Watabe et al. 1986) of paramyosin against the total myofibrillar protein. Paramyosin is a dimer of approximately $100 \mathrm{kDa}$ subunits and forms a coiled-coil structure like the myosin rod (Watabe and Iwasaki 2000; Kajita et al. 2018). This protein also forms a thick filament under physiological ionic strength and is localized at the core of the invertebrate thick filament, where myosin molecules cover the surface (Oiwa et al. 1998). Its biological function is not yet clear, though it has been considered to be involved in the 'catch mechanism' of bivalves, which can keep their shells closed tightly for a long time without energy expenditure. Paramyosin is solubilized at high salt concentration and forms a gel when heated, like myosin. The thermal gel is rigid but less elastic as compared to myosin and is not reinforced (or cross-linked) by transglutaminase in the presence of $\mathrm{Ca}^{2+}$ (Yoshida et al. 2003). Moreover, the gelation mechanism is considered to be different from that of actomyosin (Fukuda et al. 2006).

\section{Actin}

Actin constitutes approximately $20 \%$ of myofibrillar protein. In the presence of ATP, a globular (pear-shaped) monomer (G-actin) is polymerized into a double helix filament (a thin filament or F-actin), which has a rosary-like conformation. The actin filaments are recognized as a light band (isotropic band, I band) under the microscopic observation of striated muscles. The actin molecule consists of the large domains designated as $\alpha$ and $\beta$ with a cleft between them, and further divided into the four subdomains designated one through four (Fig. 1c) (Dominguez and Holmes 2011). It contains the binding sites for ATP and $\mathrm{Ca}^{2+}$ in the cleft. Actin is also known as a multifunctional protein responsible for a variety of cell motilities in combination with many partner proteins, called actin-binding proteins (Pollard 2016).

Actin is roughly categorized into six isoforms, namely, $\alpha$-type (skeletal, cardiac, and smooth muscles), $\beta$-type (sarcoplasm), and $\gamma$-type (smooth muscle, sarcoplasm) (Bertola et al. 2008; Simiczyjew et al. 2017). However, actin is considered to be a very conservative protein against molecular evolution, because the amino acid sequences even from different sources are highly identical (Morita 2003; Ochiai et al. 2013). The tertiary structures of actins from squid mantle and rabbit skeletal muscles are almost completely overlaid (Fig. 1c). The study of Ochiai et al. (2013) revealed that the amino acid sequence identities of actins from four different species of cephalopods were about $98 \%$, with the substitutions mainly located in subdomains 3 and 4, whereas Morita (2003) showed that the skeletal actins of the deep-sea gadoid Coryphaenoides species differ only at three residues. Moreover, molecular dynamics (MD) simulation has also demonstrated that high hydrostatic pressure favors the stabilization of the deep-sea actin (Wakai et al. 2014).

Nine actin genes have been characterized in the tiger puffer Takifugu rubripes (Venkatesh et al. 1996), while two isoforms have been found in the dark muscles of salmonid fish, with one similar to the fast muscle and cardiac muscle types and the other with 12 substitutions compared with the fast muscle type. These isoforms differ from each other in myosin activation profile and thermal stability (Mudalige et al. 2007; Mercer et al. 2011). $\alpha$-Actin from carp skeletal muscle shows a lower affinity for ATP and $\mathrm{Ca}^{2+}$ compared with those of their rabbit counterpart, probably due to the lower structural stability.

\section{Tropomyosin}

Tropomyosin is a dimer of the subunits of 284 amino acid residues, in most vertebrate and many shellfish (Iwasaki et al. 1997; Perry 2001; Ochiai et al. 2003; Motoyama et al. 2006, 2007). Its structure is characterized by a parallel $\alpha$-helical coiled-coil along the entire molecule, with a length of approximately $40 \mathrm{~nm}$ and width of approximately $2 \mathrm{~nm}$ (Fig. 1b). Each dimer polymerizes with adjacent molecules at the $\mathrm{N}$ - and C-termini, forming a head-to-tail filamentous fiber (Sousa and Farah 2002) unlike myosin that 
forms filaments through side-by-side polymerization under a physiological condition. Tropomyosin resides along the groove of F-actin and interacts with seven actin monomers and one troponin complex. Tropomyosin regulates muscle contraction in cooperation with troponin (actin-linked regulation of muscle contraction, in contrast to the myosin-linked regulation found in some invertebrates) (Perry 2001).

Mammalian striated muscle tropomyosin consists of $\alpha$ (TPM1) and $\beta$ (TPM2) isoforms, which derive from different genes (Perry 2001), while the counterparts of fish striated muscles are homogeneous, consisting of $\alpha$ isoform only. The fast muscle tropomyosin in bluefin tuna Thunnus orientalis, however, exceptionally consists of two isoforms, both of which are close to mammalian $\alpha$-tropomyosin but not to $\beta$-tropomyosin (Ochiai et al. 2010a). The substitutions of the amino acid are scattered along the entire molecules of the two isoforms, suggesting that these isoforms are not the splicing variants from a single gene, but encoded by different genes. In puffer $T$. rubripes fast muscle, two $\alpha$-tropomyosin genes are transcribed (Ikeda et al. 2003), but the gene composition is different from that in tuna. In the tropomyosin genes of $T$. rubripes, the counterparts for all the mammalian tropomyosin genes (TM-1, -2, -3, and -4) were found, in addition to many splicing variants and the duplicate genes for TM-1 and TM-4 (Toramoto et al. 2004). The heterogeneity in the protein level has been confirmed for these tropomyosins (Huang and Ochiai 2005).

The scallop adductor muscle consists of yellowish striated muscle and whitish smooth muscle, and three isoforms of tropomyosin have been found in the smooth muscle of Yesso scallop Mizuhopecten yessoensis (Hasegawa 2001). The positions of the amino acid substitutions among these three isoforms are characterized by a few clusters, suggesting that these isoforms are the splicing variants, but only one protein was found in the striated muscle, whereas the opaque portion of smooth muscle contains two isoforms (IshimodaTakagi and Kobayashi 1987). Ozawa et al. (2010) isolated the major isoform, which was identified as that reported by Hasegawa (2001). The isoform in the translucent portion located between the opaque and striated muscles seems to be the same as the major isoform in the opaque portion (Ishimoda-Takagi and Kobayashi 1987).

\section{Thermal stability}

Though fish fast muscle tropomyosins, which are generally $\alpha$ type, show high amino acid sequence identity (>95\%) to each other, they show clear differences in thermal stability (Huang and Ochiai 2005; Huang et al. 2019). Tropomyosin is thus considered to be an excellent model protein for the investigation of the structure-stability relationship, like the myosin rod, with the additional advantage of its high solubility under low ionic strength, unlike the myosin rod.

Since the coiled-coil structure of tropomyosin unfolds by thermal treatment in a less complicated manner, the thermostability has been intensively measured for many fish species (Ochiai et al. 2003, 2010a; Huang et al. 2004; Huang and Ochiai 2005) and also for invertebrates (Ozawa et al. 2010). The decay of $\alpha$-helical and coiled-coil structures can be evaluated by CD and DSC like the myosin rod. Clear differences in thermal stability and denaturation profiles have also been reported for those from the cardiac and dark muscles of brown trout Salmo trutta, with the stability of the latter being higher (Jackman et al. 1996). Tropomyosins from the tropical fish species (such as milkfish, tilapia) were generally thermostable compared with those from cold-water species, with a few exceptions (Huang et al. 2019). In some cases, glycine, an $\alpha$-helix breaker, was considered to be responsible for reduced thermostability (Huang and Ochiai 2005; Ozawa et al. 2011). In Atlantic salmon Salmo salar tropomyosin, the 179th threonine residue was found to be greatly responsible for the thermal instability and stabilized when replaced by alanine (Fudge and Heeley 2015). Besides, when the 24th and 27th glycine residues were replaced by alanine, the recombinant protein became more resistant to thermal treatment and chymotryptic digestion. Regarding the stability differences between the molecular regions, the $\mathrm{N}$-terminal half of shortfin mako shark Isurus oxyrinchus tropomyosin was found to be more thermostable compared with the remainder (Hayley et al. 2011). On the other hand, in scallop striated muscle tropomyosin, the stability of the C-terminal region was found to be higher than that of the $\mathrm{N}$-terminal region, indicating that the stability of this protein is not homogeneous along the entire fibrous molecule (Ozawa et al. 2010). In tuna T. orientalis fast muscle tropomyosin as described above, there can be the three combinations of two isoforms ( $\alpha$ and $\beta$ chains), and the stability of the $\beta$ homodimer reconstituted from the isolated subunits was found to the lowest (Ochiai et al. 2010a). Such differences in the stability of isoforms could be related to the migratory profiles and behaviors of tunas.

\section{Allergenicity}

Tropomyosins are known to be the major allergen of crustaceans and mollusks, though their content is as low as a few milligrams per g muscle (Faber et al. 2017; Ruethers et al. 2018). Vertebrate tropomyosins, on the contrary, are not regarded as allergens generally, with some exceptions of tilapia (Liu et al. 2013). The amino acid sequence identities between fish and invertebrate tropomyosins are as low as $60 \%$ (Ozawa et al. 2011). As the other allergens, tropomyosin hardly aggregates even at high temperatures (Ozawa et al. 2017). By taking the advantage of higher solubility 
of invertebrate tropomyosin in water, the content of shrimp tropomyosin could be reduced to $1.6 \times 10^{-5}$ folds by boiling treatment (Ozawa et al. 2020), suggesting that boiling is expected as a possible hypoallergenic treatment.

Kuruma prawn $M$. japonicus tropomyosin, however, showed resistance against digestion in the stomach (Kunimoto et al. 2011). Since proteinases tend to attack the unfolded regions of proteins (Hubbard et al. 1998), high stability results in the resistance against digestion. Actually, the prawn tropomyosin showed high thermostability when compared with the scallop counterpart (Fig. 2a; Ozawa et al. 2011). Thermodynamic analyses revealed that the stability of invertebrate tropomyosins was in the order of prawn $>$ abalone $>$ squid (Ozawa et al. 2011).
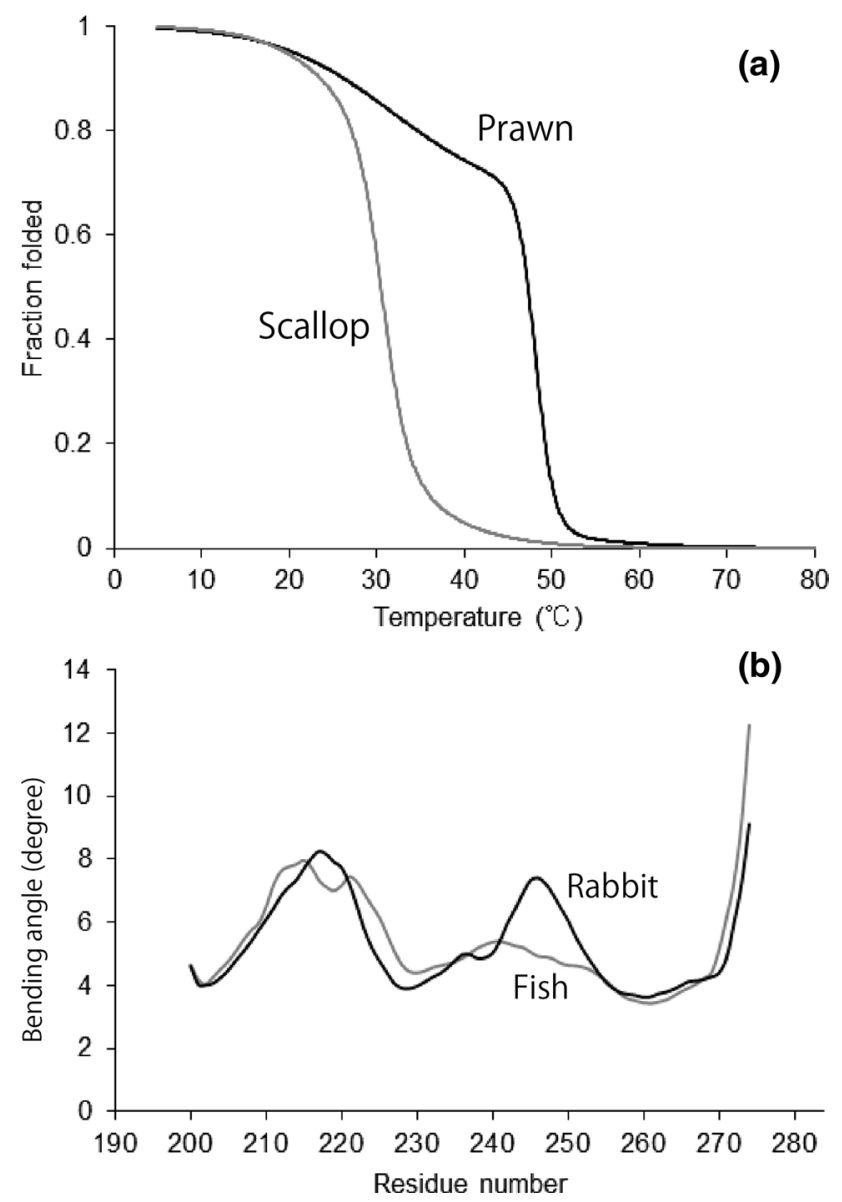

Fig. 2 a The $\alpha$-helical contents of striated muscle tropomyosins from kuruma prawn M. japonicus and Yesso scallop Mizuhopecten yessoensis as measured by circular dichroism. The $\alpha$-helical contents were estimated by the molar ellipticity at $222 \mathrm{~nm}$. The $\alpha$-helical contents at $5{ }^{\circ} \mathrm{C}$ and $80^{\circ} \mathrm{C}$ were regarded as 1 and 0 , respectively (Ozawa et al. 2010, 2011). b Bending angles of the C-terminal fragments (190th-284th residues) of fish (white croaker Pennahia argentata) and rabbit Oryctolagus cuniculus tropomyosins based on molecular dynamics simulation for $20 \mathrm{~ns}$. The amino acid substitutions between these tropomyosins were located at the 191st, 229th, 247th, and 252nd residues
MD simulations of proteins can predict their behaviors, by numerically solving the equations for their motion under a given condition (Salomon-Ferrer et al. 2013). It is still controversial whether the binding of tropomyosin to actin filament is in a pre-shaping manner or an induced fit manner. In the former, tropomyosin takes a curved stiff structure (Holmes and Lehman 2008), and in the latter a flexural flexible one (Brown et al. 2001). To understand the binding dynamics, MD simulations have been intensively performed (Li et al. 2010; Zheng et al. 2013). However, it is still not clear which attribute is essential for the binding of the two proteins. The simulation showed that the bending is sensitive only to the limited number of amino acid substitutions (Fig. 2b). MD simulation of the thin filament, consisting of actin, tropomyosin, and troponin, was performed in the presence and absence of $\mathrm{Ca}^{2+}$ to understand how amino acid substitutions of thin filament proteins would contribute to the adaptation for the environments, at atomic resolution (Manning et al. 2011). In addition, the allergenicity of tropomyosin has also been challenged by MD simulation. An allergic reaction is caused by the binding of immunoglobulin E (IgE) to epitope regions of proteins, which should be resistant to digestion in the stomach. By MD simulations, the epitope regions of prawn tropomyosin were found to have higher $\alpha$-helical contents and lower flexibility of dihedral angles, in other words, rigid and much less subject to unfolding and digestion, when compared to the non-epitope regions (Ozawa et al. 2018).

\section{Troponin}

Troponins are found in the striated muscles across the animal kingdom, even the lower invertebrates such as Platyhelminthes and Nematoda, but not in Echinodermata (Obinata et al. 2014) or Cnidaria (jellyfish) (Tanaka et al. 2018). Troponin is a complex of three subunits called T, I, and C. Of these, the T subunit binds to tropomyosin. In contrast, the I subunit inhibits the interaction of myosin and actin, and the $\mathrm{C}$ subunit triggers muscle contraction through the dynamic structural change upon $\mathrm{Ca}^{2+}$ binding (Vinogradova et al. 2005). The troponin complex, consisting of each one of these subunits, binds to tropomyosin filament periodically (every $40 \mathrm{~nm}$, corresponding to seven actins). Troponin C has a dumbbell-like structure, with two $\mathrm{Ca}^{2+}$ binding sites located at each of the $\mathrm{N}$ - and $\mathrm{C}$-termini. The linker region is considered to have a flexible structure, which has been confirmed through MD simulations (Bowman and Lindert 2019). This protein is considered comparatively conservative because it shows high similarity in amino acid sequences, as evidenced by the existence of a $70 \%$ identity between lamprey and human skeletal muscle troponin Cs. Troponin $\mathrm{C}$ also has a similarity to the other $\mathrm{Ca}^{2+}$ binding proteins, 
such as calmodulin and myosin light chains. The $\mathrm{Ca}^{2+}$ binding properties of troponin Cs between fast muscle type and cardiac muscle type, which is also expressed in slow muscle, has been shown to be different (Gillis et al. 2007). The cardiac troponin $\mathrm{C}$ of rainbow trout changes its $\mathrm{Ca}^{2+}$ binding ability through acclimation to habitat temperature, and the structure of the inhibitory region of troponin I is greatly affected by the presence of $\mathrm{Ca}^{2+}$ (Gillis and Tibbits 2002). In this sense, troponin $\mathrm{C}$ is an interesting target for the study of the structure-function relationship. In fish troponin Ts, five isoforms with different molecular weight and amino acid sequences have been found in Atlantic salmon $S$. salar with three and two subunits for the fast and slow muscles, respectively (Waddleton et al. 1999).

Invertebrate troponins differ clearly from those of the vertebrates (Cao et al. 2019). The molecular weights of the T, $\mathrm{I}$, and $\mathrm{C}$ subunits from scallop adductor smooth muscle are approximately $40 \mathrm{kDa}, 19 \mathrm{kDa}$, and $20 \mathrm{kDa}$, respectively (Nishita et al. 1997), with that of the T subunit being higher than those of mammalian troponin Ts. The identity of amino acid sequences between human and scallop is approximately $20 \%$. Invertebrate troponin Ts have an additional C-terminal region of about 50 residues, which is rich in glutamic acid. Troponin Is, including those of invertebrates, have the N-terminal region spanning around one-third of the molecule, being responsible for $\mathrm{Ca}^{2+}$-dependent regulation (Tanaka et al. 2005). Scallop troponin $\mathrm{C}$ has four $\mathrm{Ca}^{2+}$ binding sites, but only the fourth site from the N-terminus (site IV) is considered as an active binding site (Nishita et al. 1994).

\section{Myoglobin}

This protein generally exists in a large amount in the sarcoplasm of aerobic muscle cells. The redness of muscle is roughly proportional to myoglobin content, and thus the changes in this protein, mostly redox state of the heme iron, greatly affect the coloration of muscle. Most fish myoglobins consist of 143 amino acids, shorter than the mammalian counterparts by about five amino acids, and the molecular weight is around $17 \mathrm{kDa}$ (Table 1). Myoglobin has one heme which binds the oxygen molecule (Fig. 3). The presence of the iron atom at the center of the heme gives this protein its red color. Oxidation of the heme iron proceeds as a firstorder reaction (Fig. 4) (Chow et al. 2009), and thus the rate illustrates the denaturation profile of this protein under different $\mathrm{pH}$, temperature, and salt concentration, etc. (Ueki et al. 2005; Ochiai et al. 2010b; Nurilmala et al. 2018). Its visible absorption spectrum also depicts the structural and redox level changes, and such characteristics extend it as a model protein for structural analyses. Furthermore, myoglobin has a high helical content and thus is an excellent

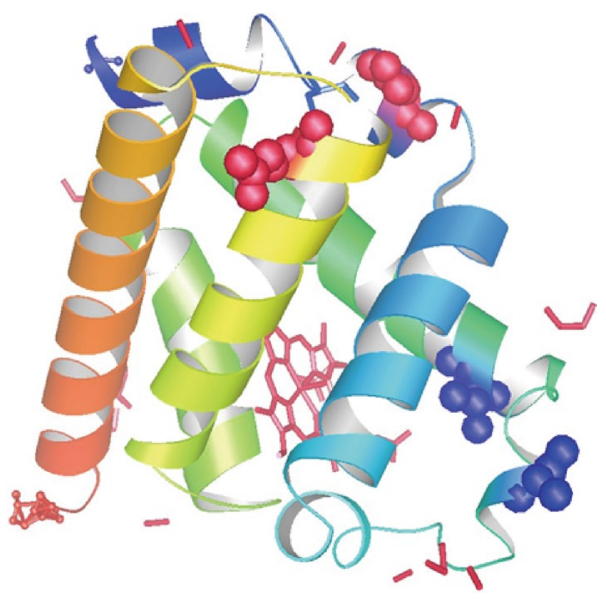

Fig. 3 Modeled structure of bigeye tuna myoglobin based on yellowfin tuna myoglobin (1MYT). The heme is shown in a stick model. The residues (13th, 21st, 57th, and 63rd), which greatly affect the stability, are shown in a ball model. The viewpoints of the structures have been arranged so that the structural differences and the locations of the residues are highlighted

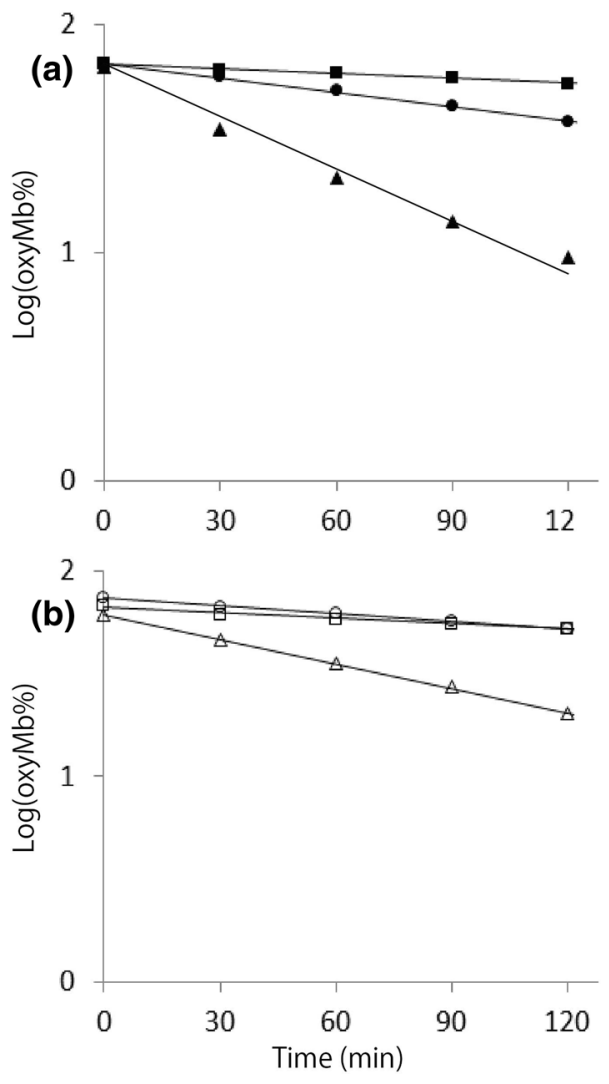

Fig. 4 Effects of temperature and $\mathrm{pH}$ on the autoxidation of myoglobin at $37{ }^{\circ} \mathrm{C}$. The ratios of oxymyoglobin against the total myoglobin during incubation were plotted as a first-order reaction. a Bluefin tuna myoglobin, b horse myoglobin. In both figures, the squares, circles, and triangles represent $\mathrm{pH} 7.4,6.5$, and 5.6, respectively 


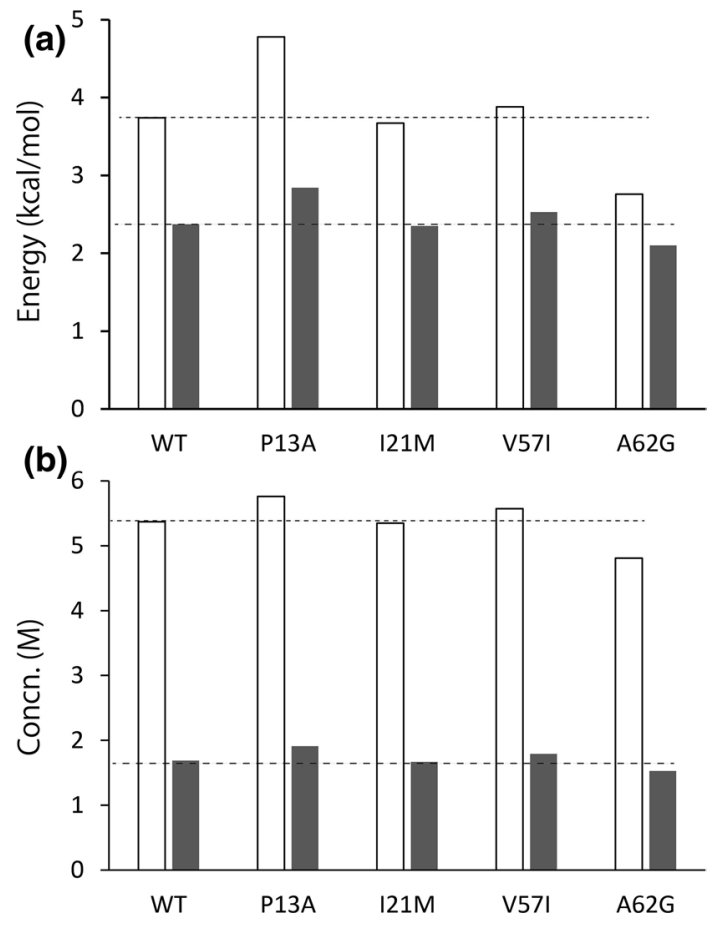

Fig. 5 The differences in stability between the myoglobin mutants of single residue substitutions using the recombinant bigeye tuna myoglobin as a wild type (WT). a Standard free energy of unfolding. b Transition midpoint of the denaturant concentration for the complete unfolding of bigeye tuna myoglobin mutants. Open and closed bars represent the data in the presence of urea and guanidine hydrochloride as protein denaturants, respectively (Ueki and Ochiai 2006). The horizontal broken lines indicate the values for the wild-type myoglobin with no substitution. P13A, I21M, V57I, and A62G are the mutants with single mutations at the designated residues (each mutant name consists of the residue in bigeye tuna myoglobin followed by the residue number and the substituted residue)

target to examine the structure-stability relationship like tropomyosin.

The studies on tuna myoglobins revealed that limited numbers of residues are responsible for the difference in thermal stability (Ueki and Ochiai 2004). When several residues that differ between the myoglobins from different tuna species have been mutated (Fig. 3), dramatic changes in thermal stability were recognized, as shown in Fig. 5. Above all, the substitutions of the 13th proline by alanine in bigeye tuna myoglobin increased the resistance to denaturation by protein denaturants (urea, guanidine hydrochloride) (Ueki and Ochiai 2006). The other mutations also showed a clear increase or decrease in thermal stability as well (Ochiai et al. 2009). These results suggest that there are a limited number of amino acid residues, which control the overall stability of the molecule. It means that the organisms can adapt to respective habitat environment and optimize the functions of proteins by tuning the sequence of the key molecules at the minimal level. Similar molecular adaptations have been found in the actin and myosin from deep-sea fish species as well as salmon tropomyosin as described above.

\section{Parvalbumin}

Parvalbumin, with a molecular weight of about $11 \mathrm{kDa}$, is a $\mathrm{Ca}^{2+}$ binding protein, which has a binding motif (EFhand) consisting of two $\alpha$-helices. E and F helices stand for the fifth and sixth helices from the $\mathrm{N}$-terminus of the molecule. Such a structure is shared by many $\mathrm{Ca}^{2+}$ binding proteins such as troponin $\mathrm{C}$ (described above) and calmodulin. Higher vertebrates do not have this protein in their muscles, but do in the nervous tissues. Parvalbumin is found in the fast skeletal muscle of teleost, but not in their dark and cardiac muscles. The content is higher in the dorsal part than the ventral part, and also high in the parts close to the head (Kobayashi et al. 2016). The physiological function has not been fully characterized, but it is assumed to be involved in locomotion ability and muscle relaxation, because the expression level and isoform composition are quite species-specific (Schoenman et al. 2010; Campion et al. 2012). Isoform composition is characterized by species specificity in molecular weight, isoelectric point, and molar ratio.

Parvalbumin is a very stable protein, and thus does not aggregate (or stays soluble) even under drastic processing of fish muscle (Kanamori et al. 2011); therefore, it can be extracted from thoroughly processed fish muscle. In this relation, this protein is one of the major allergens in fish muscle (Ruethers et al. 2018). The key residues in the epitope of mackerel Scomber japonicas parvalbumin (Sco j 1) have been annotated to its tertiary structure, with three out of four residues being exposed to the surface (Kumeta et al. 2017). On the other hand, some attempts have been made to apply this protein for species identification by taking advantage of the high thermostability and extractability from processed muscle, in addition to species specificity as described above (Carrera et al. 2006, 2012).

Tremendous efforts have been made so far to reveal the properties of muscle proteins from fish and shellfish, despite the difficulties in their handling due to their instability, which poses a serious bottleneck for researchers. This review discussed the biochemical and physicochemical properties of the striated muscle proteins and described their structure-stability relationships. This study will be of great benefit in the effective utilization of aquatic bioresources, as well as for the many unexplored species. Moreover, the application of MD simulations will further aid in exploring other aspects of the already studied proteins.

Acknowledgements We would like to thank all who have been involved in the field studies and all the funding which has made the 
related studies successful. We also would like to thank Editage for English language editing.

Open Access This article is licensed under a Creative Commons Attribution 4.0 International License, which permits use, sharing, adaptation, distribution and reproduction in any medium or format, as long as you give appropriate credit to the original author(s) and the source, provide a link to the Creative Commons licence, and indicate if changes were made. The images or other third party material in this article are included in the article's Creative Commons licence, unless indicated otherwise in a credit line to the material. If material is not included in the article's Creative Commons licence and your intended use is not permitted by statutory regulation or exceeds the permitted use, you will need to obtain permission directly from the copyright holder. To view a copy of this licence, visit http://creativecommons.org/licenses/by/4.0/.

\section{References}

Bertola LD, Ott EB, Griepsma S, Vonk FJ, Bagowski CP (2008) Developmental expression of the alpha-skeletal actin gene. BMC Evol Biol 8:166

Bowman JD, Lindert S (2019) Computational studies of cardiac and skeletal troponin. Front Mol Biosci. https://doi.org/10.3389/ fmolb. 2019.00068

Brown JH, Kim KH, Jun G, Greenfield NJ, Dominguez R, Volkmann N, Hitchcock-DeGregori SE, Cohen C (2001) Deciphering the design of the tropomyosin molecule. Proc Natl Acad Sci USA 98:8496-8501

Campion LA, Choi S, Mistry HL, Coughlin DJ (2012) Myosin heavy chain and parvalbumin expression in swimming and feeding muscles of centrarchid fishes: the molecular basis of the scaling of contractile properties. Comp Biochem Physiol 163A:223-230

Cao T, Thongam U, Jin JP (2019) Invertebrate troponin: Insights into the evolution and regulation of striated muscle contraction. Arch Biochem Biophys 666:40-45

Carrera M, Cañas B, Piñeiro C, Vázquez J, Gallardo JM (2006) Identification of commercial hake and grenadier species by proteomic analysis of the parvalbumin. Proteomics 6:5278-5287

Carrera M, Cañas B, Gallardo JM (2012) Rapid direct detection of the major fish allergen, parvalbumin, by selected MS/MS ion monitoring mass spectrometry. J Proteom 75:3211-3220

Chow CJ, Yang JI, Lee PF, Ochiai Y (2009) Structural and autooxidation profiles of myoglobins from three species and one hybrid of tilapia (Cichlidae, Perciformes). Comp Biochem Physiol 154B:274-281

de Boer J, Schöslerb H, Aiking H (2020) Fish as an alternative protein-a consumer-oriented perspective on its role in a transition towards more healthy and sustainable diets. Appetite 152:104721

Dinh TNL, Watabe S, Ochiai Y, Hashimoto K (1985) Myosin light chains from the cardiac muscle of mackerel, Pneumatophorus japonicus japonicus. Comp Biochem Physiol 80B:203-207

Dominguez R, Holmes KC (2011) Actin structure and function. Annu Rev Biophys 40:169-186

Faber MA, Pascal M, El Kharbouchi O, Sabato V, Hagendorens MM, Decuyper II, Bridts CH, Ebo DG (2017) Shellfish allergens: tropomyosin and beyond. Allergy 72:842-848

FAO (Food and Agriculture Organization) (2013) FAOSTAT Food Supply Database. Accessed 6 June 2020

Franzini-Armstrong C, Sweeney HL (2012) The contractile machinery of skeletal muscle. In: Hill JA, Olson EN (eds) Muscle: fundamental biology and mechanisms of disease. Academic Press, London, pp 823-840
Fudge KR, Heeley DH (2015) Biochemical characterization of the roles of glycines 24 and 27 and threonine 179 in tropomyosin from the fast skeletal trunk muscle of the Atlantic salmon. Biochemistry 54:2769-2776

Fukuda N, Fujiura M, Kimura M, Nozawa SN (2006) Thermally induced gelation of paramyosin from scallop adductor muscle. Fish Sci 72:1261-1268

Fukushima H, Satoh Y, Nakaya M, Ishizaki S, Watabe S (2003) Thermal effects on fast skeletal myosins from Alaska pollock, white croaker, and rabbit in relation to gel formation. J Food Sci 68:1573-1577

Gauvry L, Ennion S, Ettelaie C, Goldspink G (2000) Characterisation of red and white muscle myosin heavy chain gene coding sequences from antarctic and tropical fish. Comp Biochem Physiol 127B:575-588

Gillis TE, Tibbits GF (2002) Beating the cold: the functional evolution of troponin $\mathrm{C}$ in teleost fish. Comp Biochem Physiol 132A:763-772

Gillis TE, Marshall CR, Tibbits GF (2007) Functional and evolutionary relationships of troponin C. Physiol Genom 32:16-27

Guhathakurta P, Prochniewicz PE, Thomas DD (2018) Actin-myosin interaction: structure, function and drug discovery. Int J Mol Sci 19:2628

Hamai M, Konno K (1990) Structural stability of fish myosin subfragment-1. Comp Biochem Physiol 95B:255-259

Hartman MA, Spudich JA (2012) The myosin superfamily at a glance. J Cell Sci 125:627-1632

Hasegawa Y (2001) Complete nucleotide sequences of cDNA encoding for tropomyosin isoforms from the catch muscle of scallop Patinopecten yessoensis. Fish Sci 67:988-990

Hashimoto K, Watabe S, Kono M, Shiro M (1979) Muscle protein composition of sardine and mackerel. Nippon Suisan Gakkaishi 45:1435-1441

Hayley M, Chevaldina T, Heeley DH (2011) Cold adaptation of tropomyosin. Biochemistry 50:6559-6566

Hirayama Y, Kanoh S, Nakaya M, Watabe S (1997) The two essential light chains of carp fast skeletal myosin, LC1 and LC3, are encoded by distinct genes and change their molar ratio following temperature acclimation. J Exp Biol 200:693-701

Holmes KC, Lehman W (2008) Gestalt-binding of tropomyosin to actin filaments. J Muscle Res Cell Motil 29:213-219

Huang MC, Ochiai Y (2005) Fish fast skeletal muscle tropomyosins show species-specific thermal stability. Comp Biochem Physiol 141B:461-471

Huang MC, Ochiai Y, Watabe S (2004) Structural and thermodynamic characterization of tropomyosin from fast skeletal muscle of bluefin tuna. Fish Sci 70:667-674

Huang MC, Lee CL, Ochiai Y, Watabe S (2019) Thermostability of tropomyosins from the fast skeletal muscles of tropical fish species. Fish Physiol Biochem 45:1189-1202

Hubbard SJ, Beynon RJ, Thornton JM (1998) Assessment of conformational parameters as predictors of limited proteolytic sites in native protein structures. Protein Eng 11:349-359

Ikeda D, Toramoto T, Ochiai Y, Suetake H, Suzuki Y, Minoshima S, Shimizu N, Watabe S (2003) Identification of novel tropomyosin 1 genes of pufferfish (Fugu rubripes) on genomic sequences and tissue distribution of their transcripts. Mol Biol Rep 30:83-90

Ishimoda-Takagi T, Kobayashi M (1987) Molecular heterogeneity and tissue specificity of tropomyosin obtained from various bivalves. Comp Biochem Physiol 88B:443-452

Iwasaki K, Kikuchi K, Funabara D, Watabe S (1997) cDNA cloning of tropomyosin from the anterior byssus retractor muscle of mussel and its structural integrity from the deduced amino acid sequence. Fish Sci 63:731-734 
Jackman DM, Waddleton DM, Younghusband B, Heeley DH (1996) Further characterisation of fast, slow and cardiac muscle tropomyosins from salmonid fish. Eur J Biochem 242:363-371

Kajita T, Takeda Y, Yoshida S, Yamada K, Matsumiya M, Fukushima $\mathrm{H}$ (2018) cDNA cloning of paramyosin from several kinds of squid mantle muscle. Adv Biosci Biotechnol 9:11-25

Kanamori M, Tanaka H, Hamada Y, Nagashima Y, Shiomi K (2011) New extraction method suitable for immunoblotting analysis of fish allergens. Eur Food Res Technol 233:991-997

Kanoh S, Taniguchi J, Yamada T, Niwa E (2000) Effects of urea on surface hydrophobicity of requiem shark myosin. Fish Sci 66:801-803

Kariya Y, Ochiai Y, Hashimoto K (1986) Protein components and ultrastructure of the arm and mantle muscles of octopus Octopus vulgaris. Nippon Suisan Gakkaishi 52:131-138

Kobayashi Y, Yang T, Yu CT, Ume C, Kubota H (2016) Quantification of major allergen parvalbumin in 22 species of fish by SDS-PAGE. Food Chem 194:345-353

Kumeta H, Nakayama H, Ogura K (2017) Solution structure of the major fish allergen parvalbumin Sco $\mathrm{j} 1$ derived from the Pacific mackerel. Sci Rep 7:17160

Kunimoto A, Yokoro M, Murota K, Yamanishi R, Suzuki-Yamamoto T, Suzuki M, Yutani C, Doi S, Hiemori M, Yamashita H, Takahashi Y, Tsuji H, Kimoto M (2011) Gastrointestinal digestion and absorption of Pen $\mathrm{j} 1$, a major allergen from Kuruma prawn, Penaeus japonicus. Biosci Biotechnol Biochem 75:1249-1258

Li XE, Holmes KC, Lehman W, Jung H, Fischer S (2010) The shape and flexibility of tropomyosin coiled coils: implications for actin filament assembly and regulation. J Mol Biol 395:327-339

Libera LD, Carpene E, Theibert J, Collins JH (1991) Fish myosin alkali light chains originate from two different genes. J Muscle Res Cell Motil 12:366-371

Liu R, Holck AL, Yang E, Liu C, Xue W (2013) Tropomyosin from tilapia (Oreochromis mossambicus) as an allergen. Clin Exp Allergy 43:365-377

Manning EP, Tardiff JC, Schwartz SD (2011) A model of calcium activation of the cardiac thin filament. Biochemistry 50:7405-7413

Matulef K, Sirokman K, Perreault-Micale CL, Szent-Györgyi AG (1998) Amino-acid sequence of squid myosin heavy chain. J Muscle Res Cell Motil 19:705-712

Mercer RC, Mudalige WA, Ige TO, Heeley DH (2011) Vertebrate slow skeletal muscle actin-conservation, distribution and conformational flexibility. Biochim Biophys Acta 1814:1253-1260

Morita T (2003) Structure-based analysis of high pressure adaptation of $\alpha$-actin. J Biol Chem 278:28060-28066

Morita T (2008) Comparative sequence analysis of myosin heavy chain proteins from congeneric shallow- and deep-living rattail fish (genus Coryphaenoides). J Exp Biol 211:1362-1367

Motoyama K, Ishizaki S, Nagashima Y, Shiomi K (2006) Cephalopod tropomyosins: identification as major allergens and molecular cloning. Food Chem Toxicol 44:1997-2002

Motoyama K, Suma Y, Ishizaki S, Nagashima Y, Shiomi K (2007) Molecular cloning of tropomyosins identified as allergens in six species of crustaceans. J Agric Food Chem 55:985-991

Mudalige WA, Jackman DM, Waddleton DM, Heeley DH (2007) A vertebrate slow skeletal muscle actin isoform. FEBS $\mathbf{J}$ 274:3452-3461

Nishita K, Tanaka H, Ojima T (1994) Amino acid sequence of troponin $\mathrm{C}$ from scallop striated adductor muscle. J Biol Chem 269:3464-3468

Nishita K, Ojima T, Takahashi A, Inoue A (1997) Troponin from smooth adductor muscle of Ezo-giant scallop. J Biochem 121:419-424

Nurilmala M, Ushio H, Ochiai Y (2018) pH- and temperature-dependent denaturation profiles of tuna myoglobin. Fish Sci 84:579-587
Nyitray L, Jansco A, Ochiai Y, Graf L, Szent-Györgyi AG (1994) Scallop striated and smooth muscle myosin heavy-chain isoforms are produced by alternative RNA splicing of a single gene. Proc Natl Acad Sci 91:12686-12690

Obinata T, Amemiya S, Takai R, Ichikawa M, Toyoshima YY, Sato N (2014) Sea lily muscle lacks a troponin-regulatory system, while it contains paramyosin. Zool Sci 31:122-128

Ochiai Y, Kariya Y, Watabe S, Hashimoto K (1985) Heat-induced tendering of turban shell (Batillus cornutus) muscle. J Food Sci 50:981-984

Ochiai Y, Kariya Y, Hashimoto K (1988) Biochemical and structural heterogeneity of fast and slow muscles of the blue crab Portunus trituberculatus. Comp Biochem Physiol 90B:355-360

Ochiai Y, Handa A, Kobayashi T, Watabe S, Hashimoto K (1989) Isolation and enzymatic properties of myosin subfragment-1 isozymes from the ordinary muscle of tilapia Oreochromis niloticus. Nippon Suisan Gakkaishi 55:2143-2149

Ochiai Y, Kobayashi T, Watabe S, Hashimoto K (1990) Mapping of fish myosin light chains by two-dimensional gel electrophoresis. Comp Biochem Physiol 95B:341-345

Ochiai Y, Huang MC, Fukushima H, Watabe S (2003) cDNA cloning and thermodynamic properties of tropomyosin from walleye pollack Theragra chalcogramma. Fish Sci 69:1031-1039

Ochiai Y, Ueki N, Watabe S (2009) Effects of point mutations on the structural stabilities of tuna myoglobins. Comp Biochem Physiol 153B:223-228

Ochiai Y, Ozawa H, Huang MC, Watabe S (2010a) Characterization of two tropomyosin isoforms from the fast skeletal muscle of bluefin tuna Thunnus thynnus orientalis. Arch Biochem Biophys 502:96-103

Ochiai Y, Watanabe Y, Ozawa H, Ikegami S, Uchida N, Watabe S (2010b) Thermal denaturation profiles of tuna myoglobin. Biosci Biotechnol Biochem 74:1673-1679

Ochiai Y, Watabe S, Wang G (2013) Structural and phylogenetic profiles of muscle actin from cephalopods. J Biol Appl Sci 9:606-614

Oiwa K, Yamaga T, Yamada A (1998) Direct observation of a central bare zone in a native thick filament isolated from the anterior byssus retractor muscle of Mytilus edulis using fluorescent ATP analogue. J Biochem 123:614-618

Okagaki T, Takami M, Hosokawa K, Yano M, Higashi-Fujime S, Ooi A (2005) Biochemical properties of ordinary and dark muscle myosin from carp skeletal muscle. J Biochem 138:255-262

Ozawa H, Watabe S, Ochiai Y (2010) Thermostability of striated and smooth adductor muscle tropomyosins from Yesso scallop Mizuhopecten yessoensis. J Biochem 147:823-832

Ozawa H, Watabe S, Ochiai Y (2011) Thermodynamic characterization of muscle tropomyosins from marine invertebrates. Comp Biochem Physiol 160B:64-71

Ozawa H, Koyama M, Ishizaki S, Ochiai Y (2017) Effect of boiling on the elution of the major allergen tropomyosin from shrimp and squid muscles. Food Sci Technol Res 23:41-43

Ozawa H, Umezawa K, Takano M, Ishizaki S, Watabe S, Ochiai Y (2018) Structural and dynamical characteristics of tropomyosin epitopes as the major allergens in shrimp. Biochem Biophys Res Commun 498:119-124

Ozawa H, Yamamura A, Kimijima T, Ishizaki S, Ochiai Y (2020) Elimination of the major allergen tropomyosin from shrimp muscle by boiling treatment. Fish Sci 86:197-202

Perry SV (2001) Vertebrate tropomyosin: distribution, properties and function. J Muscle Res Cell Motil 22:5-49

Pollard TD (2016) Actin and actin-binding proteins. Cold Spring Harb Perspect Biol 8:a018226

Ruethers T, Taki AC, Johnston EB, Nugraha R, Le TTK, Kalic T, McLean TR, Kamath SD, Lopata AL (2018) Seafood allergy: 
A comprehensive review of fish and shellfish allergens. Mol Immunol 100:28-57

Salomon-Ferrer R, Case DA, Walker RC (2013) An overview of the Amber biomolecular simulation package. WIREs Comput Mol Sci 3:198-210

Satoh Y, Nakaya M, Ochiai Y, Watabe S (2006) Characterization of fast skeletal myosin from white croaker in comparison with that from walleye pollack. Fish Sci 72:646-655

Schoenman ER, Chiaro JA, Jones A, Bastin LD, Coughlin DJ (2010) A comparative analysis of parvalbumin expression in pinfish (Lagodon rhomboides) and toadfish (Opsanus sp.). Comp Biochem Physiol 155A:91-99

Shuman JL, Coughlin DJ (2018) Red muscle function and thermal acclimation to cold in rainbow smelt, Osmerus mordax, and rainbow trout, Oncorhynchus mykiss. J Exp Zool A Ecol Integr Physiol 329:547-556

Simiczyjew A, Pietraszek-Gremplewicz K, Mazur AJ, Nowak D (2017) Are non-muscle actin isoforms functionally equivalent? Histol Histopathol 32:1125-1139

Somero GN (2003) Protein adaptations to temperature and pressure: complementary roles of adaptive changes in amino acid sequence and internal milieu. Comp Biochem Physiol 136B:577-591

Sousa AD, Farah CS (2002) Quantitative analysis of tropomyosin linear polymerization equilibrium as a function of ionic strength. J Biol Chem 277:2081-2088

Tanaka H, Takeya Y, Doi T, Yumoto F, Tanokura M, Ohtsuki I, Nishita $\mathrm{K}$, Ojima T (2005) Comparative studies on the functional roles of $\mathrm{N}$ - and C-terminal regions of molluskan and vertebrate troponinI. FEBS J 272:4475-4486

Tanaka H, Ishimaru S, Nagatsuka Y, Ohashi K (2018) Smooth musclelike $\mathrm{Ca}^{2+}$-regulation of actin-myosin interaction in adult jellyfish striated muscle. Sci Rep 8:7776

Toramoto T, Ikeda D, Ochiai Y, Minoshima S, Shimizu N, Watabe S (2004) Multiple gene organization of pufferfish Fugu rubripes tropomyosin isoforms and tissue distribution of their transcripts. Gene 331:41-51

Ueki N, Ochiai Y (2004) Primary structure and thermostability of bigeye tuna myoglobin in relation to those of other scombroid fishes. Fish Sci 70:874-884

Ueki N, Ochiai Y (2006) Effect of amino acid replacements on the structural stability of fish myoglobin. J Biochem 140:649-656

Ueki N, Chow CJ, Ochiai Y (2005) Characterization of bullet tuna myoglobin with reference to the thermostability-structure relationship. J Agric Food Chem 53:4968-4975

Venkatesh B, Tay BH, Elgar G, Brenner S (1996) Isolation, characterization and evolution of nine pufferfish (Fugu rubripes) actin genes. J Mol Biol 259:655-665

Vinogradova MV, Stone DB, Malanina GG, Karatzaferi C, Cooke R, Mendelson RA, Fletterick RJ (2005) $\mathrm{Ca}^{2+}$-regulated structural changes in troponin. Proc Natl Acad Sci 102:5038-5043
Waddleton DM, Jackman DM, Bieger T, Heeley DH (1999) Characterisation of troponin-T from salmonid fish. J Muscle Res Cell Motil 20:315-324

Wagner PD, Slayter C, Pope B, Weeds AG (1979) Studies on actinactivation on myosin subfragment-1 isozymes and the role of myosin light chains. Eur J Biochem 99:385-394

Wakai N, Takemura K, Morita T, Kitao A (2014) Mechanism of deepsea fish $\alpha$-actin pressure tolerance investigated by molecular dynamics simulations. PLoS ONE 9:e85852

Wang GF, Watabe S, Ochiai Y (2018) Characterization of myosin heavy chains from the mantle muscles of cephalopods. J Biochem Biotechnol 1:34-41

Watabe S (2002) Temperature plasticity of contractile proteins in fish muscle. J Exp Biol 205:2231-2236

Watabe S, Iwasaki K (2000) Complete amino acid sequence of Mytilus anterior byssus retractor paramyosin and its putative phosphorylation site. J Exp Zool 286:24-35

Watabe S, Ochiai Y, Hashimoto K (1982) Identification of 5,5'-dithiobis 2-nitrobenzoic acid (DTNB) and alkali light chains of piscine myosin. Nippon Suisan Gakkaishi 48:827-832

Watabe S, Hashimoto K, Watanabe S (1983) The pH-dependency of myosin ATPases from yellowtail ordinary and dark muscles. J Biochem 94:1867-1875

Watabe S, Ochiai Y, Kariya Y, Dinh TNL, Kimura S, Pyeung JH, Hashimoto K (1986) Characterization of three types of turban shell Batillus cornutus muscle-ultrastructure and protein composition. Nippon Suisan Gakkaishi 52:737-744

Yancey PH, Fyfe-Johnson AL, Kelly RH, Walker VP, Auñón MT (2001) Trimethylamine oxide counteracts effects of hydrostatic pressure on proteins of deep-sea teleosts. J Exp Zool 289:172-176

Yoshida W, Kunimi O, Fujiura M, Kimura M, Nozawa H, Seki N (2003) Thermal gelation of salted paste from scallop striated adductor muscle. Fish Sci 69:1017-1025

Yuan C, Wang X, Chen S, Qu Y, Konno K (2011) Structural stability of myosin rod from silver carp as affected by season. J Food Sci 76:C686-693

Zheng W, Barua B, Hitchcock-DeGregori SE (2013) Probing the flexibility of tropomyosin and its binding to filamentous actin using molecular dynamics simulations. Biophys J 105:1882-1892

Publisher's Note Springer Nature remains neutral with regard to jurisdictional claims in published maps and institutional affiliations. 